\title{
Mecanismos alternativos de resolução de litígios em matéria fiscal internacional
}

https://doi.org/10.21814/uminho.ed.30.15

\author{
João Sérgio Ribeiro \\ Professor Associado da Escola de Direito da \\ Universidade do Minho
}

\section{Introdução}

As situações em que diferentes Estados interpretam ou aplicam de forma diferente as disposições dos acordos ou convenções para eliminar a dupla tributação, no âmbito da tributação do rendimento e património, podem criar uma carga fiscal excessiva para as empresas. São, além disso, suscetíveis de criar distorções e ineficiências económicas. Por esse motivo, é necessário que existam mecanismos que garantam uma resolução eficaz desses litígios.

Depois de vermos como o problema é abordado no domínio da Convenção Modelo da OCDE em matéria de impostos sobre o rendimento e sobre o património (CMO$(\mathrm{CDE})$, devotaremos a nossa atenção à Diretiva Europeia relativa aos mecanismos de resolução de litígios em matéria fiscal para dar conta, em linhas gerais, das soluções que propõe. Terminaremos com a sugestão de uma via alternativa, no plano do de iure condendo, para resolver as problemáticas analisadas.

\section{A solução no domínio da CMOCDE}

O recurso mais prático, e às vezes a única possibilidade, para resolver conflitos, no domínio da CMOCDE, é o procedimento por mútuo acordo (PMA). Este mecanismo, consubstanciado no artigo $25 .^{\circ}$ da CMOCDE, é um procedimento bilateral por meio do qual o contribuinte tem a possibilidade de apresentar o seu caso às autoridades competentes dos Estados envolvidos, quando considerar que a aplicação das disposições fiscais não foi feita de acordo com a convenção. Para isso, não é necessário que os impostos já tenham sido cobrados, bastando que o contribuinte presuma que os impostos serão cobrados de forma contrária ao tratado.

Embora popular, a eficácia do PMA tem vindo a ser questionada por várias razões.

Em primeiro lugar, o PMA termina muitas vezes sem êxito, ou seja, sem que se chegue a um acordo, o que é potenciado pelo facto de, ao abrigo do Artigo $25 .^{\circ}$, n. $^{\circ} 2$, 
da CMOCDE, as autoridades competentes terem apenas de "envidar esforços" para resolver o caso. Não estando, portanto, obrigadas a resolver o diferendo.

Em segundo lugar, existe a desvantagem de, mesmo que o resultado seja um acordo, ele não ter de ser alcançado dentro de um prazo específico.

Em terceiro lugar, existe outro inconveniente, concretamente o envolvimento limitado do contribuinte no PMA que parece restringido, na maioria das situações, ao direito de o iniciar. Sendo, depois disso, improvável que a participação do contribuinte continue no procedimento.

Por último, também é problemático que o PMA não seja transparente e que o contribuinte não tenha conhecimento dos motivos que estão na base do acordo.

Essas e outras características insatisfatórias do PMA levaram a uma alteração importante ao artigo $25 .^{\circ}$, na atualização da CMOCDE de 2008, através da inclusão de uma cláusula de arbitragem no artigo $25 .^{\circ}$, n. $^{\circ}$ 5, da CMOCDE. Essa disposição passou a determinar que, após a apresentação do caso pelo contribuinte nos termos do artigo $25 .^{\circ}$, n. $^{\circ} 1$, da CMOCDE, e na eventualidade de as autoridades competentes não conseguirem chegar a um acordo para o resolver, no prazo de dois anos, as questões pendentes devem ser submetidas à arbitragem. A introdução da arbitragem como um mecanismo de resolução de litígios foi reforçada com a versão de 2017 da CMOCDE que a converteu em mecanismo obrigatório (muito por influência do Plano de Ação da OCDE Base Erosion na Profit Shifting).

Convém salientar, porém, que este tipo particular de arbitragem não foi concebido como um mecanismo independente ou automático de resolução de litígios, mas, sim, como um procedimento auxiliar, complementar do PMA, a que só se pode recorrer quando, no âmbito daquele, as autoridades competentes não conseguirem chegar a um acordo.

Conforme estabelecido pelo artigo $25 .^{\circ}$, n. $^{\circ}$ 5, alínea b), da CMOCDE, outras características importantes desse tipo de arbitragem são: (i) uma solicitação de arbitragem não pode ser feita se uma decisão sobre as questões não resolvidas já tiver sido proferida por um tribunal ou tribunal administrativo de qualquer um dos Estados; (ii) via de regra, o contribuinte, para exercer a arbitragem, também deve renunciar ao seu direito a recursos internos sobre a mesma questão ${ }^{1}$ e (iii) o procedimento dessa arbitragem deve ser decidido por mútuo acordo e a decisão decorrente da arbitragem será vinculativa para ambos os Estados contratantes.

Do que foi descrito acima, pode concluir-se que existe uma grande diferença entre esse tipo de arbitragem e a arbitragem normalmente concebida em outros contextos, como a arbitragem comercial ou a solução de controvérsias no contexto da Organização Mundial do Comércio.

1 Ver comentário ao artigo $25^{\circ}$, n. $^{\circ}$ 5, §82, da CMOCDE. 


\section{A solução trazida pela Diretiva relativa aos mecanismos de resolução de litígios em matéria fiscal na União Europeia}

A União Europeia tem uma longa história em termos de utilização da arbitragem como ferramenta para resolver litígios fiscais. Não podemos esquecer a Convenção de Arbitragem 90/436 CEE, de 23 de julho de 1990, sobre a Eliminação da Dupla Tributação em Relação à Correção de Lucros das Empresas Associadas. No entanto, este instrumento tinha um alcance muito limitado, na medida em que abrangia principalmente questões de preços de transferência. Além disso, a Convenção de Arbitragem não era um instrumento jurídico ao abrigo do direito da União Europeia, o que implicou que não fosse automaticamente adotada por todos os Estados-Membros. Em consequência desta última característica, o Estado-Membro tem sempre a possibilidade de denunciar unilateralmente a Convenção de Arbitragem.

Com a aprovação da Diretiva 2017/1857 do Conselho, de 10 de outubro de 2017, relativa aos mecanismos de resolução de litígios em matéria fiscal na União Europeia, sem prejuízo de se aproveitar a experiência da Convenção de Arbitragem, tenta-se superar muitas de suas lacunas e também ir para além do seu escopo. Independentemente de alguma sobreposição com a Convenção de Arbitragem, a Diretiva não foi criada para a revogar, tal como resulta de vários momentos do seu preâmbulo.

A Diretiva 2017/1857 tem muitas semelhanças com os desenvolvimentos que analisámos no quadro da OCDE. Da mesma forma que a arbitragem, no âmbito da OCDE, foi integrada no PMA, também no contexto da Diretiva, uma fase em tudo semelhante a uma arbitragem (por via de uma Comissão Consultiva ou de uma Comissão de Resolução Alternativa de Litígios) foi integrada no congénere PMA. Só podendo, por consequência, ser solicitada quando, no âmbito deste, não se consegue resolver o litígio.

A Comissão Consultiva corresponde aproximadamente ao Painel de Árbitros da OCDE quando a arbitragem é adotada. A Comissão de Resolução Alternativa de Controvérsias é diferente da Comissão Consultiva, em termos de composição, e representa uma porta de entrada para outras formas de resolução de litígios, como a arbitragem de "oferta final", conciliação e mediação.

Assim, caso o litígio não seja resolvido entre as autoridades competentes no PMA, o contribuinte pode solicitar a constituição de uma Comissão Consultiva. A Comissão Consultiva é composta pelas autoridades competentes dos Estados-Membros em litígio e por três personalidades independentes (uma das quais preside). Essas pessoas são selecionadas a partir de uma lista elaborada para fins específicos, para a qual são nomeadas, pelos Estados-Membros, em conformidade com a Diretiva.

As autoridades competentes com assento na Comissão Consultiva devem chegar a acordo sobre as regras do procedimento e divulgá-las. Uma vez estabelecida, a Comissão Consultiva deve emitir o seu parecer no prazo de 6 meses. 
Depois de a Comissão Consultiva emitir o seu parecer, este é notificado às autoridades competentes. Com base neste parecer, as autoridades dos Estados-Membros em causa tomam uma decisão final. Se não conseguirem chegar a um acordo sobre uma decisão final atempadamente, o parecer torna-se vinculativo para essas autoridades. A decisão definitiva é aplicada sob reserva de o interessado ou interessados aceitarem essa decisão e renunciarem ao direito a qualquer recurso nacional².

Os detalhes das decisões são publicados online.

Apesar das semelhanças, diríamos que a Diretiva incorpora uma versão mais refinada dos desenvolvimentos da OCDE, garantindo que a resolução de litígios sugerida pelos planos de ação da BEPS é implementada de forma organizada, harmonizada e sólida na União Europeia. Há, porém, algumas diferenças, como as que se seguem.

O PMA proposto na Diretiva tem um prazo de dois anos ${ }^{3}$, o que é uma melhoria face ao tradicional PMA da CMOCDE, impedindo que este se estenda indefinidamente.

As regras sobre a forma das reclamações e as informações que devem ser fornecidas $^{4}$, assim como as regras sobre a resolução de litígios (incluindo o envolvimento da Comissão Consultiva e o seu trabalho na resolução dos litígios) também são mais detalhadas, o que aumenta a segurança jurídica.

As decisões finais são sempre publicadas na íntegra ou, no mínimo, sob a forma resumida ${ }^{5}$.

Os direitos do contribuinte também parecem estar mais garantidos, na medida em que a participação é muito maior. Os contribuintes, com o consentimento das autoridades competentes dos Estados-Membros, comparecem ou são representados perante a Comissão Consultiva ou a Comissão de Resolução Alternativa de Litígios ${ }^{6}$.

A diferença mais relevante é a opção que é dada aos Estados-Membros de beneficiarem de mecanismos alternativos de resolução de litígios, como a mediação, a conciliação, em vez da arbitragem.

É verdade que também no contexto da OCDE, nos termos do artigo $25 .^{\circ}$, n..$^{\circ} 4 \mathrm{CMO}$ CDE (versão de 2017), há margem para admitir mecanismos alternativos, o que é reforçado pelos parágrafos 86 e 87 do comentário a esse artigo, ao permitir, abertamente, outros mecanismos de resolução suplementares. No entanto, essa opção é muito mais evidente no contexto da Diretiva, onde tem um valor jurídico totalmente diferente, no sentido de que não é considerada apenas soft law, mas hard law.

2 Ver artigo $15 .^{\circ}$, n. ${ }^{\circ}$ 4, da Diretiva 2017/1857 do Conselho, de 10 de outubro de 2017, doravante Diretiva.

3 Ver artigo $4 .^{\circ}$ da Diretiva.

4 Ver artigo $3 .^{\circ}$ da Diretiva.

5 Ver artigo $18 .^{\circ}$ da Diretiva.

6 Ver artigo $13 .^{\circ}$, n. $^{\circ} 2$, da Diretiva. 
Uma das implicações do reforço do valor jurídico da Diretiva é o facto de prevalecer sobre outros instrumentos, nomeadamente os tratados fiscais, em geral. 0 que significa que se esses procedimentos tiverem sido iniciados simultaneamente com os da Diretiva, devem ser encerrados assim que a Comissão Consultiva ou a Comissão de Resolução Alternativa de Litígios for nomeada7.

\section{Outra solução possível}

Não obstante as evoluções positivas no âmbito da CMOCDE e consideráveis progressos no âmbito da Diretiva que acabámos de abordar, parece-nos que a resolução dos litígios poderia beneficiar grandemente com outro tipo de desenvolvimentos. Vejamos.

A melhor solução, mesmo que não seja uma panaceia para todos os desafios, seria que, paralelamente à arbitragem, existisse um tribunal internacional para resolver litígios relativos aos tratados fiscais. Podendo, no contexto específico da União Europeia, o Tribunal de Justiça da União Europeia (TJUE) desempenhar esse papel.

A inspiração pode ser tirada do tratado entre a Alemanha e a Áustria e da decisão do TJUE, C-648/15, de 12 de setembro de 2017, que foi desencadeada no âmbito desse tratado.

A convenção entre a Áustria e a Alemanha é única em que, nos termos do seu artigo $25 .^{\circ}$, n. $^{\circ} 5$, em caso de dificuldades ou dúvidas quanto à interpretação ou aplicação das suas disposições, para as quais não seja possível encontrar solução no âmbito de um PMA entre as autoridades competentes, no prazo de três anos a contar do início desse procedimento, os Estados são obrigados, a pedido do contribuinte, a submeter o litígio ao TJUE. Deverão fazê-lo, no âmbito de um procedimento de arbitragem, nos termos do artigo $273 .^{\circ}$ do Tratado sobre o Funcionamento da União Europeia (TFUE).

O aspeto mais interessante do processo C-648/15 não é a questão material em causa, mas o facto de o TJUE, ao reconhecer a sua competência nos termos do artigo 273 . $^{\circ}$ do TFUE para decidir o caso, ter funcionado como tribunal arbitral.

Pensamos que esta solução é bastante inspiradora e capaz de garantir um bom grau de harmonização no domínio da resolução de litígios. Isso sem prejuízo de poderem ser apresentados vários argumentos contra ela, designadamente o facto de poder dizer-se que os juízes do TJUE não são especialistas em tratados tributários, ou até, que, na maioria dos casos, tentam proteger as liberdades fundamentais a todo o custo, muitas vezes colocando uma pressão insustentável sobre os princípios universais de direito tributário.

7 Ver comentário ao artigo $25 .^{\circ}$, n. ${ }^{\circ}$ 5, mutatis mutandis, § 67, da CMOCDE. 
Essas observações não devem ser suficientes para rejeitar o envolvimento dos juízes do TJUE em questões tributárias, existindo também muitos argumentos a seu favor. Vejamos alguns deles ${ }^{8}$.

Gostaríamos de lembrar, a título de contraponto, que O TJUE lidou com essas questões várias vezes e o número crescente de processos fiscais certamente desenvolverá a familiaridade dos juízes com esses casos.

Além disso, uma abordagem mais geral das questões relativas aos tratados tributários pode ter vantagens, pois os juízes, não obstante a excelente capacidade de adaptação às diferentes áreas do direito têm, ainda assim, uma visão menos condicionada dos assuntos fiscais. Isto é, estão geralmente mais livres de pré-compreensões.

Ao contrário, os árbitros são especialistas na área, o que implica que tenham pré-entendimentos e posicionamentos já enraizados, sendo muito provável que os continuem a seguir no caso de serem envolvidos. Além disso, eles são muitas vezes selecionados pelas posições que reiteradamente vão seguindo, o que pode tornar o envolvimento de juízes profissionais, o mais apropriado.

Os procedimentos seguidos pelo TJUE são mais estáveis, o que gera uma maior segurança para os contribuintes. Contrariamente, os procedimentos de arbitragem são muito diversos e nem sempre fáceis de harmonizar com o direito interno.

Ressalta-se, ainda, que a execução de decisões arbitrais nem sempre é fácil, tendo em vista que os contribuintes dispõem de meios para recusar uma decisão arbitral, tanto nas convenções que seguem o Modelo da $\mathrm{OCDE}^{9}$, como na Diretiva relativa aos mecanismos de resolução de litígios em matéria fiscal ${ }^{10}$; que contrasta claramente com a execução de decisões do TJUE que não podem ser recusadas pelos contribuintes.

Depois, as decisões do TJUE, além de vinculativas para os contribuintes, são vinculativas também para os Estados que não podem recusá-las, mesmo que delas discordem. 0 mesmo não acontece no contexto da Convenção Modelo da OCDE ${ }^{11}$ ou da Diretiva sobre resolução de litígios ${ }^{12}$, porque os Estados podem decidir desviar-se da opinião da decisão arbitral.

Por fim, é importante destacar que o envolvimento do TJUE tem um efeito dissuasor em relação ao não compromisso por parte do Estados, pois o tratado entre a Áustria

8 Ver STARINGER, Claus, Austria: CJUE Pending Case from Austria - Austria/Germany (C-648/15), in LANG, Michael et al (eds), “CJUE Recent Developments in Direct Taxation - 2016”, Linden, Viena, 2017, págs. 1-10, que seguimos muito de perto.

9 Ver artigo $25 .^{\circ}$, n. ${ }^{\circ}$ 5., alínea b), da CMOCDE.

10 É necessário que decisão seja aceite pelos interessados. Ver artigo $15^{\circ}$, n. $^{\circ}$ 4, da Diretiva.

11 Ver artigo 25..$^{\circ}$. ${ }^{\circ}$ 5., alínea b), da CMOCDE.

12 Ver artigo $15^{\circ},{ }^{\circ} .^{\circ}$, da Diretiva. 
e a Alemanha, embora em vigor há 19 anos ${ }^{13}$, só relativamente há pouco tempo é que desencadeou o envolvimento do TJUE como tribunal arbitral.

Por tudo o que foi dito, a criação de um tribunal fiscal internacional ou, enquanto esta ideia não se concretizar, a participação do TJUE no contexto estrito dos Estados-Membros da União Europeia pode ser considerada como uma solução interessante, a ponderar.

\section{Conclusão}

Os desenvolvimentos recentes ocorridos, quer no domínio da OCDE quer da União Europeia, afirmaram a arbitragem como um mecanismo alternativo de resolução de litígios em matéria fiscal internacional. Sem prejuízo de estas evoluções se caracterizarem por conferirem à arbitragem uma lógica de acessoriedade e de dependência face aos PMAs, não deixam, ainda assim, de ser louváveis.

Consideramos, todavia, que estes progressos devem ser complementados pelo envolvimento crescente de verdadeiros tribunais supranacionais, sendo o exemplo da Convenção Alemanha/Áustria, e consequente intervenção do TJUE, um importante primeiro passo. Dominado ainda pela lógica da arbitragem, é certo, mas, apesar de tudo, muito válido.

13 Celebrada em 24 de agosto de 2000, em vigor desde 2002. 